\title{
Development of a Web-Site for the Education College of Human Science at Kerbala University
}

\author{
Haider Sahib Nasrallah $^{1 *}$, Kadum Ali Ahmed ${ }^{1}$, Muneer Sameer Gheni Mansoor ${ }^{2}$ \\ ${ }^{1}$ Computer Division, Education College for Human Science / Kerbala University, Kerbala, Iraq \\ ${ }^{2}$ Department of Communication and Mobile Computing Engineering, College of Engineering/ University of Information Technology \\ and Communications, Baghdad, Iraq
}

DOI: $10.36348 /$ sb.2019.v05i10.004 $\quad$ | Received: 10.08 .2018 | Accepted: 18.08 .2018 | Published: 30.10 .2019

*Corresponding author: Haider Sahib Nasrallah

\section{Abstract}

The use of the Internet is very wide, which led to the ease of access to information from anywhere in the world, with minimal effort and shortest amount of time, that teachers and students in colleges and universities are more class looking for information related to their studies and their work, such as scientific research, books and lectures. Today, The wide spread of the Internet especially the websites of governments and organizations to publicize information about their activities and services. Recent years, the number of users and Beneficiaries of these sites has increased rapidly and continuously. This requires careful planning and preparation to achieve the purpose of developing those websites. This paper proposes the development of a web site for college based on modern techniques such as Python and Django framework.

Keywords: Django Framework, Python, SQLITE, Website.

Copyright @ 2019: This is an open-access article distributed under the terms of the Creative Commons Attribution license which permits unrestricted use, distribution, and reproduction in any medium for non-commercial use (NonCommercial, or CC-BY-NC) provided the original author and source are credited.

\section{INTRODUCTION}

The development witnessed by the world in the field of information technology and communications, the evolution of the computer industry, operating systems and multiple, which is one of the features of this present century. The use of technology in the access to information and transfer is the most important pillars that will enable us to keep pace with development and progress in all fields, in addition to the impact on saving time, effort and money, whether in the field of access to information, transported, or stored. Thanks to the evolution of the concept and uses of information technology and the Internet, the world is becoming like a small global village. Internet provides many services, among them Communication services, e-mail, knowledge and browsing, storage services, entertainment, banking services and commercial services. The world today League online, and we can say that the Internet has become an integral part of our lives. Since the colleges and universities are considered the source of science and modern technology, it must be the first in the use of these new technologies in learning and education service, especially after the widespread use of computers, internet in different fields at universities such as education, dissemination of scientific research and get the latest information. An example of this is Education College for Human Science at Kerbala University, It has a site but it, contain little information about the college, can be considered as a site for news or media [1]. We decided to develop a special site for Education College for Human Science at Kerbala University, based on modern information technologies.

\section{THE PRACTICAL SIGNIFICANCE}

This project is useful for the teaching staff and students in Education College for Human Science at the University of Kerbala, because it contains several features to assist the teaching staff and students, such as the following:

1. Saving the time and efforts while finding the information at site;

2. Uploading and downloading study materials for students;

3. Easily dealing with the site for its friendlyman design;

4. Fastly, reliably, easily to use and to have high security due to the standard tools of SQLITE [2];

5. Unlimited number of users; 
6. Ability for the following development of the site.

\section{THE PROBLEM STATEMENT}

In our project, we want to develop site for Education College for Human Sciences at Kerbala University, when developing a website we have to include into this site all information pertaining to the college. To become a user of the site, a student after registering on the site, obtains the information he needs very easily and is pleased at any time, from anywhere.

The site will contain the information about the following basis:

1. Lectures;

2. Dates of lectures;

3. Students and their grades;

4. Teachers and their specialty;

5. College conferences and news.

6. Scientific and administrative departments of the College;

7. Showing scientific research for teachers and students of the college.

\section{THE USED DEVELOPMENT TOOLS}

The site will be developed using the Linux operating system, Linux is an open source operating system, and is one of the systems that are defined as UNIX [3]. This system was built the efforts of thousands of volunteers and employees of companies began in 1985 and to this day. The goal of building this system is to provide a high-performance operating system, free system, free of viruses and make the text of an open source system. The advantages are enormous. First, it is much easier to program in a high-level language. Programs written in a high-level language take less time to write, they are shorter and easier to read, and they are more likely to be correct. Second, high-level languages are portable, meaning that they can run on different kinds of computers with few or no modifications. Low-level programs can run on only one kind of computer and have to be rewritten to run on another. Python is also very popular language in web development [4], though primarily on the 'back end' side. The combination of easy extensibility, good iteration time, and good integration with database and other web standards makes it a popular choice [5]. We will use framework Django for development of a site, Django is a free and open-source web framework, written in Python, Django provides a high-level framework that enables you to build Web applications with relatively few lines of code. It is simple, robust, and flexible, allowing you to design solutions without much overhead $[6,7]$. which follows the model-viewcontroller (MVC) architectural pattern which greatly helps in building clean and maintainable web applications [8, 9]. It is maintained by the Django Software Foundation (DSF), an independent organization established as a non-profit.

\section{USE CASE DIAGRAM}

An use case diagram is a sequence of steps describing an interaction between a user and a system. Use case are unique in their ability to help teams understand the value the system must provide for its stakeholders, because use case describe how users use the system and what the system does for those users $[10,11]$. Use cases describe the way the user will interact with the system and how the system will respond him. The main purpose of the use case diagram is to help development teams to visualize the functional requirements of a system, including the relations between "actors" (human beings who will interact with the system) and essential processes (use cases). The result of developing the use case model is shown at the Fig-1.

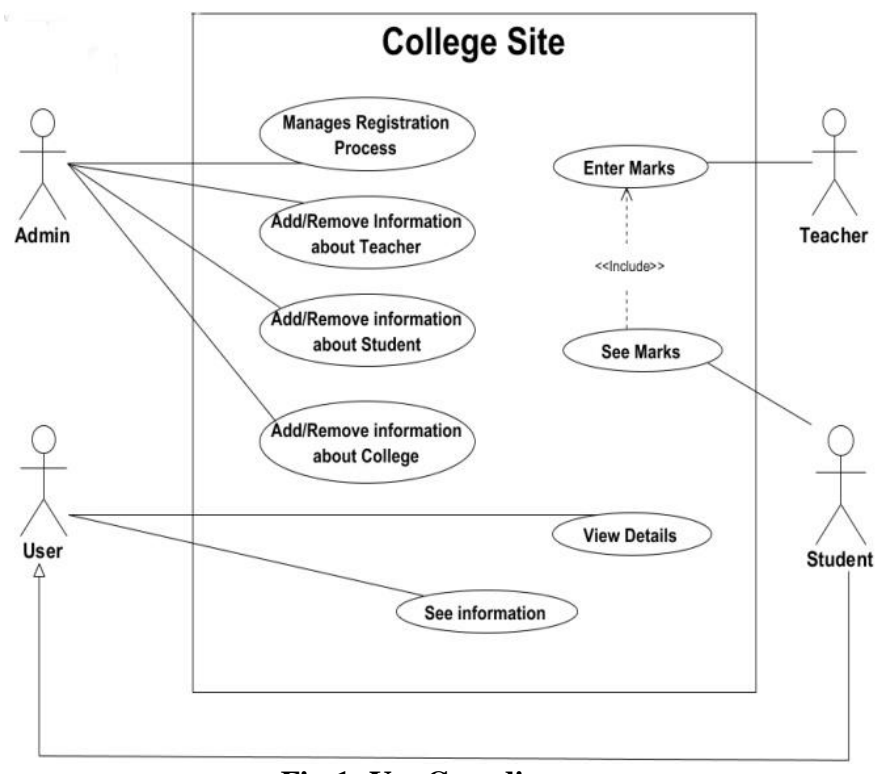

Fig-1: Use Case diagram 
Functions performed by the admin, the teacher and student. Admin functions is responsible for the registration/authorization process to enter the site, managing the teacher, student and courses information, the names of the graduating students and their rates, conferences and activities of the college and news. Teacher functions can write scores of students, select lectures studied according to their specialty. Student functions can see the lecture dates, the exam dates and information about another student and after authorization can see their marks.

\section{DEVELOPMENT OF THE DATABASE}

Database schema of education college for human sciences at Kerbala University, which consists 7 tables. The Fig-2 illustrates tables in database.

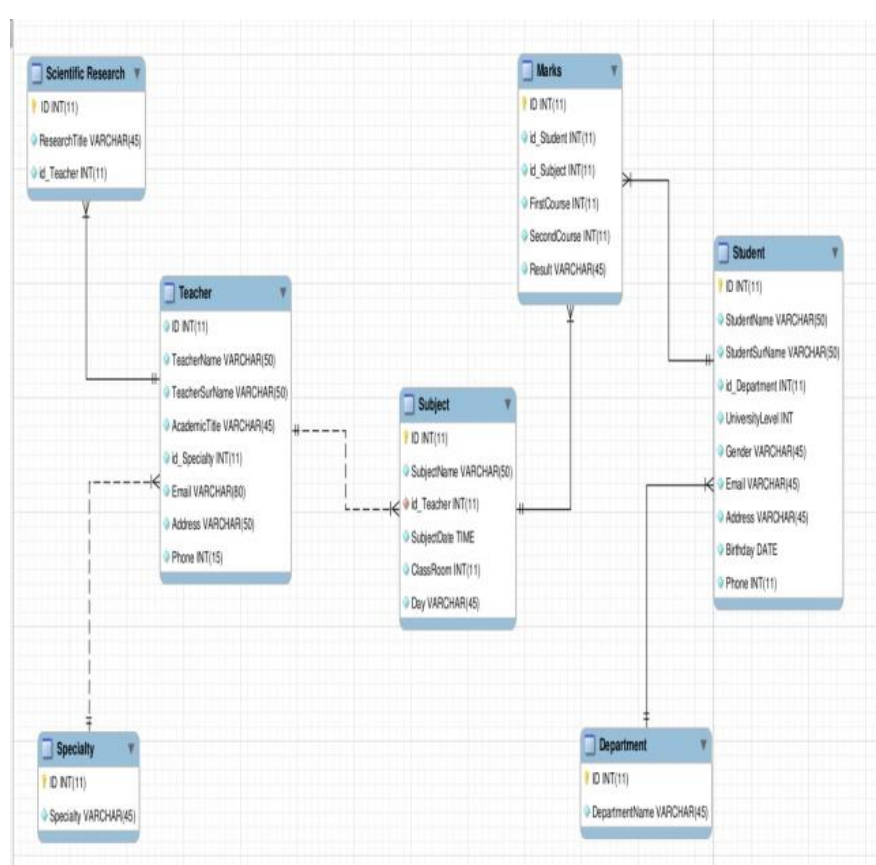

Fig-2: Database scheme

\section{FORM OF THE APPLICATION}

Any visitor can see the home page, the home page is the first in menu bar and is contains pictures for college, menu bar and college news and events such as conferences and exhibits, meetings and scientific and sports activities. It is shown in Fig-3.

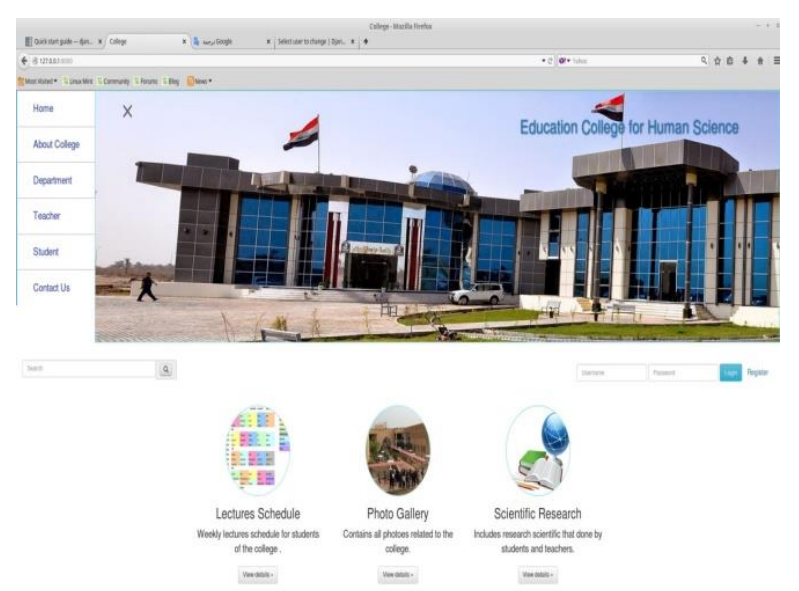

Fig-3: The home page (picture, menu bar)

\section{CONCLUSION}

Education College for Human Sciences at Kerbala University has a site with some information about the college, such as graduate students, some teachers research, faculty departments and a page in English and some college activities. That means, the current site does not contain all information related to the college, such as information about teachers, students, lectures, dates of lectures and meetings, conferences and Colleges news. During the developing of the web site, we solved the following tasks:

1. The comparative analysis of the existing sites for Education College from different countries is made;

2. The modern tools of web sites developing is studied;

3. an use case diagram is created;

4. Database scheme is created;

5. Interfaces for the site is created.

The perspectives for the developed application. Always we can think out some function, which we can implement in future for example, are the following:

1. The register processing for the students in the college will be online by the site; 
2. Download lectures students through the site;

3. Record attendance for students in college;

4. Download the duties required of students through the site.

\section{REFERENCES}

1. College for Human Sciences at Kerbala University (Iraq). (2015). [Electronic recourse] URL: http://cohe.uokerbala.edu.iq/ (the date of access: 30.04.2015).

2. Official site of SQLITE. (2016). [Electronic recourse] URL: http://www.sqlite.com/about.html (the date of access: 25.01.2016).

3. Jang, M. (2011). Linux Patch Management (USA, Prentice Hall)

4. Lei, K., Ma, Y., \& Tan, Z. (2014). Performance Comparison and Evaluation of Web Development Technologies in PHP, Python and Node.

5. Downey, A. B. (2012). Think Python (UK, O’Reilly Media).
6. Alameri, I., \& Radchenko, G. (2017). Development of Student Information Management System based on Cloud Computing Platform. The Journal of Applied Computer Science \& Mathematics, 11(2):9-14.

7. Alameri, I., \& Radchenko, G. (2016). Cloud computing and websites design and development. Lambert academic publishing.

8. Jeff, F., \& Paul, B., \& Wesley, C. (2009). Python Web Development with Django (USA, AddisonWesley).

9. Ayman, H. (2008). Learning Website Development with Django (UK, PACKT).

10. Kurt, B., \& Ian, S. (2003). Use Case Modeling (USA, Addison-Wesley).

11. Mansoor, M. S. (2015). Development of A System for Salary Calculation for Establishments In Republic of Iraq, master thesis, South Ural State University, Chelyabinsk. 